\title{
LO FANTÁSTICO, LO AGNÓSTICO Y LO ANCESTRAL EN LA LITERATURA DE JORGE LUIS BORGES
}

\author{
Norman Marín Calderón
}

\begin{abstract}
RESUMEN
Este artículo propone que el texto borgeano se puede leer a través de las coordenadas que ofrece la teoría de la literatura fantástica, a saber, la metatextualidad, el trabajo del sueño, el tiempo y el fenómeno del doble. De la misma manera, Borges emplea diferentes temas en torno a civilizaciones ancestrales y filosofías agnósticas con el propósito de corroborar la idea fundamental de su obra la que manifiesta que lo fantástico es una forma alterna de la así llamada realidad.

Palabras clave: fantástico, metatextualidad, sueño, tiempo, doble, culturas ancestrales.
\end{abstract}

\begin{abstract}
This article suggests that texts written by Borges can be read through the coordinates offered by the theory of fantastic literature; that is, metatextuality, the dream work, time, and the double. On the same token, Borges employs different themes about ancient civilizations and agnostic philosophies with the intention to corroborate the fundamental idea of his work that manifests that the fantastic is an alternate sort of the so called reality.
\end{abstract}

Key words: fantastic, metatextuality, dream, time, double, ancient civilizations.

Una de las maneras más radicales de acceder al mundo ficcional de la obra de Jorge Luis Borges (1899-1986) es partiendo de su estética escéptica sobre el Mundo así como de sus relaciones inherentes con el universo de lo fantástico, lo insólito y lo advenedizo. Por su riqueza y profundidad, los escritos borgeanos ofrecen esa capacidad de leerse de muchas maneras e interpretarlos de acuerdo a sus postulados epistémicos que le son ingénitos. Adentrarse en ellos

Ph.D. Norman Marín Calderón. Profesor interino de Inglés y Teoría Psicoanalítica. Universidad de Costa Rica. Correo electrónico: normanmarin@hotmail.com 
por medio de su carácter fantástico es una de esas posibilidades. Además de su profundidad estética y filosófica, muchos de los textos borgeanos pertenecen al orden de lo fantástico, lo agnóstico, lo extraño y lo mágico. Ya desde su formulación más conceptual, lo "fantástico" deambula por el opus borgesiano ahí donde varios de sus escritos poseen la capacidad de introducir lo inadmisible y lo quimérico en el contexto de lo comúnmente plausible.

Del mismo modo, asuntos sobre teología, culturas ancestrales, temas orientales y abundantes referencias a filosofías antiguas colaboran, en gran medida, a que el tema de lo fantástico pueda explayarse a plenitud en cada uno de esos relatos. Es por ello que imbuirse en las ficciones escritas por Borges requiere de la comprensión primordial del relato fantástico en tanto modo narrativo o subgénero de la literatura. Como cualquier otro género de discurso, el relato fantástico abriga leyes que lo rigen y le dan cabida dentro del análisis textual. Por nuestra parte, no podemos dejar de olvidar que, a fin de cuentas, para Borges, lo fantástico es una visión alterna de la realidad.

En primer lugar, el propósito cardinal de la dinámica narrativa del cuento fantástico se apoya en la premisa de que todo discurso, que en un principio parece extraño, inadmisible o extranatural, tiene la capacidad de transformarse en un relato factible y explícitamente organizado, de acuerdo a los principios narratológicos que lo albergan. A propósito, Michel Lord afirma que "la forma fantástica busca inscribir en el campo de la inteligibilidad ciertos valores de los que parece estar desprovista; incluso llega a reconstruir, aunque de forma fragmentaria, un mundo súper-organizado, al menos según las leyes de un discurso narrativo que no lo supera, en los márgenes de lo imaginario, lo más inquietante o lo más maravilloso” (1998: 17). Así, la lógica narrativa que abarca el relato fantástico se estructura a partir de cierta función "restrictiva" que le permite al texto (fantástico) cierta coherencia ahí donde lo dicho-acto de la enunciacióntendería a develarse como pura fantasía y extravío. El mismo Borges asevera que "[1]a literatura fantástica no es una evasión de la realidad, sino que nos ayuda a comprenderla de un modo más profundo y complejo" (Fernández 1988: 166). Por lo tanto, el efecto fantástico del relato estriba en la capacidad "ambivalente", pero compleja, que tiene el texto mismo de cuestionar los estamentos objetivos de la así llamada "realidad", para hacer que, aquél que se acerque al relato-personaje o lector-se sienta "forzado" a plantearse los eventos maravillosos como parte de su realidad circundante.

En este caso, el enigma que presenta el relato fantástico se ubica en el lugar de un "saber insabido" que sirve como catalizador para develar la "verdad" del texto, haciendo de ella, elemento real de ese mundo maravilloso que se nos presenta. Es decir, la escritura deviene fantástica justamente porque dos espacios se presentan simultáneamente: uno "real" que abre la situación narrativa, pero que se difumina gradualmente; y el otro-el "irreal"-que irrumpe, afirmándose a sí mismo. Esto provoca - tanto en el lector como en los actantesuna suerte de reacción discursiva que despliega la posibilidad de experimentar lo siniestro, lo mágico o, simplemente, lo fantásticamente extraño. De esta forma, podemos constatar que tanto la actitud del autor como la disposición del lector tienen relevancia composicional dentro del relato fantástico, donde cualquier tipo de vacilación condiciona, de manera radical, el efecto de conjetura dentro del universo de un retozo o de una mentira. Al respecto, en Introducción a la literatura fantástica, Tzvetan Todorov afirma que "lo fantástico es la vacilación experimentada por un ser que no conoce más que las leyes naturales, frente a un acontecimiento aparentemente sobrenatural [...]. La posibilidad de vacilar entre ambas crea el efecto fantástico [...]. El concepto de lo fantástico se define entonces a partir de su relación 
con lo real" (1981: 24-5). El texto fantástico posibilita, pues, a través de la duda que provoca, el descubrimiento de lo "impensable" y lo pone en marcha para que ese saber sin raíces se inmiscuya distorsionando lo real y presentándolo como posible y pensablemente extraño.

El efecto fantástico desplegado en un texto nace a partir de un discurso que le constituye y lo pone en movimiento dentro del relato mismo. Por lo tanto, el efecto "sobrenatural" del relato fantástico nace del lenguaje mismo. La palabra es aquí el dispositivo que permite el despliegue de lo extraño y lo mágico, y que apropia la maravilla y lo ficticio como parte de la realidad que nos incumbe. Afirma Claudio Rodríguez Fer que "la obra de Borges presupone la imposibilidad del conocimiento discursivo debido a su inevitable supeditación del lenguaje, medio expresivo que convierte en ficción cuando ingresa en su ámbito. Así, tanto la filosofía como la ciencia compartirían con la literatura [fantástica] una base igualmente fabulosa" (1998: 147). La literatura fantástica es eso: artificio verbal que abarca el mundo que habitamos, pero no lo colma. El lenguaje instala un muro infranqueable entre la palabra y la cosa produciendo siempre un crédito sobre sus propias restricciones. Vía la palabra, dice Páez Urdaneta, el discurso fantástico costea tres funciones: "una por la que conmueve, asusta o simplemente se mantiene el suspenso del lector; otra por la cual se describe un universo que no tiene, por fantástico, una realidad exterior al lenguaje, y otra por la que se produce una textura narrativa en la que lo sobrenatural rompe o restablece el equilibrio fáctico" (1988: 15).

En suma, la literatura fantástica es en sí misma una suerte de búsqueda sobre lo maravilloso, lo mágico o lo sobrenatural capaz de afirmar la existencia de una súperrealidad más allá de la cotidianidad esperada, y a la que se accede vía la palabra o la simple imaginación ahí donde el sueño, la locura, lo ilógico y lo inexplicable son formas idóneas de ejercer el acceso a otro ángulo de dicho entorno: "Desde luego no hay solución. Y si la hay, lo más probable es que no pueda ser dicha con palabras humanas. El Universo es tan complejo que no hay ninguna razón para que pueda ser expresado, sobre todo por algo tan casual como el lenguaje" (Fernández 1988: 243).

Hasta ahora hemos utilizado los vocablos "fantástico", "maravilloso" y "extraño" indistintamente. Sin embargo, Todorov hace una harta diferenciación clasificatoria de los términos que vale la pena señalar sucintamente aquí. Todorov se forja un recorrido puntual en torno al relato fantástico y sus vertientes genéricas. Las clasifica bajo los rubros de "extraño puro, fantástico-extraño, fantástico maravilloso y maravilloso puro" (1981: 38). En primer lugar, un relato es "extraño" cuando el lector tiene la posibilidad de justificar el hecho "irreal" por medio de herramientas cognoscitivas reales: "Los acontecimientos que a lo largo del relato parecen sobrenaturales, reciben, finalmente, una explicación racional" (1981: 38). El relato de un sueño, por ejemplo, se podría incluir bajo esta clasificación en tanto lo irreal (el sueño) puede ser "explicado" bajo el conocimiento humano (lo real: una explicación o interpretación lógicas). Todorov sostiene que este extrañamiento tiene la capacidad de tornarse fantástico cuando la vacilación se disipa al final de éste, clarificándose las dudas interpuestas al inicio del texto.

Todorov también introduce el término de "extraño puro" dentro de esta clasificatoria. El autor afirma que "[e]n las obras pertenecientes a ese género, se relatan acontecimientos que pueden explicarse perfectamente por las leyes de la razón, pero que son, de una u otra manera, increíbles, extraordinarios, chocantes, singulares, inquietantes, insólitos [...]" (1981: 40). El cuento de extrañamiento puro es entonces aquel relato donde, ya desde su inicio, el lector se percata de que los eventos acaecidos en el texto son irreales y que caben únicamente desde la 
"lógica" de lo increíble. En el ejemplo anterior del sueño, desde el comienzo sabemos que lo que experimentamos en el ejercicio de la lectura es un sueño. En suma, el cuento "fantásticoextraño" revela la incógnita fantástica al final del relato con el fin de suspender las certezas e implantar en el lector el sentimiento de lo ominoso, mientras que en el "extraño puro" desde el inicio sabemos que lo que vamos a leer no es del orden de lo real o lógico.

De lo extraño pasamos al ámbito de lo maravilloso (o fantástico-maravilloso). Alega Todorov que el relato se torna maravilloso cuando el lector decide aceptar nuevas leyes para explicar un fenómeno dado, admitiendo así una nueva lógica de interpretación. En otras palabras, el relato es maravilloso cuando las posibilidades hermenéuticas son insuficientes para dilucidar el hecho que se presenta, aceptando que tales eventos sólo son posibles bajo otra lógica, en otro universo, bajo una nueva interpretación. Al respecto asevera Todorov que:

\begin{abstract}
Nos encontramos en el campo de lo fantástico-maravilloso, o, dicho de otra manera, dentro de la clase de relatos que se presentan como fantásticos y que terminan con la aceptación de lo sobrenatural. Estos relatos son los que más se acercan a lo fantástico puro, pues éste, por el hecho mismo de quedar inexplicado, no racionalizado, nos sugiere, en efecto, la existencia de lo sobre-natural. El límite entre ambos será, pues, incierto, sin embargo, la presencia o ausencia de ciertos detalles permitirá siempre tomar una decisión. (1981: 44)
\end{abstract}

A partir de este punto, el autor procede a hacer una liosa clasificación del relato así llamado maravilloso, el cual divide en "hiperbólico, exótico, instrumental, científico y maravilloso puro". Este intrincado estudio le permite a Todorov hacer una exhaustiva explicación de las diferentes formas de literatura fantástica y de sus modos de representar la lógica, las leyes naturales y la realidad, el cual lo lleva a afirmar que esas formas clasificatorias son subgéneros de la literatura fantástica donde todo es obra de la imaginación, y cuyos temas y sentimientos quedan fuera del mundo considerado "real".

Estas peculiaridades del relato fantástico desplegadas por Todorov en su Introducción nos proveerá de los instrumentos necesarios para aproximarnos a los textos borgeanos desde el lugar de lo que causa duda y maravilla, o sea, desde el ámbito de la fantasía. De este modo, los textos borgeanos pueden ser leídos también como literatura fantástica. Además de Todorov, otros estudiosos trabajan el tema de lo fantástico a partir de sus causas históricas así como metafísicas. Por ejemplo, Susana Reisz de Rivarola circunscribe una formulación cabal sobre el haber de la literatura fantástica, la que define de la siguiente manera:

\footnotetext{
Proposiciones metafísicas, dogmas religiosos, creencias de mayor o menor vigencia en determinados espacios y momentos históricos, se vuelven postulados fantásticos cuando, al no ser legitimados ni denunciados como ilusorios, se incorporan al mundo miméticamente constituido en la ficción con el status de posibilidades inquietantes, dislocadas de todos los órdenes pensables, de todas las 'verdades' admitidas, de todas las certezas en que se funda un hombre de nuestros días y de nuestra cultura para ubicarse y actuar en el mundo de su experiencia. (1989: 293)
}

Por su parte, la definición que, a propósito, ofrece Roger Callois en su Antología del cuento fantástico también nos favorecerá en el intento de acercarnos a los escritos borgesianos desde esta perspectiva de lo maravilloso cuando advierte que lo fantástico acaece "cuando lo sobrenatural aparece como una ruptura de la coherencia universal. [...] Es lo imposible sobreviniendo de improvisto en un mundo donde lo imposible está desterrado por definición" (1967: 77). Bajo esta salvedad, muchos de los cuentos borgeanos pertenecen a este ámbito de la imposibilidad ya que pueden ser leídos como relatos fantásticos o como narraciones que producen "extrañamiento". De ahora en adelante, nuestro cometido (y el de Borges) será la de promover una lectura desde esta perspectiva de análisis. 
Muchos de los textos borgeanos pueden clasificarse, de acuerdo a lo expuesto anteriormente, como literatura fantástica. Primero, porque Borges descree en una teoría absoluta sobre la "realidad". Para Borges, de la realidad siempre se debe dudar. En "En las ruinas circulares (a propósito de un cuento de Borges)", Risco nos hace notar que "la duda, producida en/por el relato fantástico no es más que el reflejo de un fenómeno contradictorio producido por dicho texto" (1998: 127). Borges expurga así a la realidad de un logos esencial, afirmando su carácter imaginario y su calidad de artificio, es decir, que la realidad, según él, tiene la característica de pertenecer al ámbito de lo fantástico.

En "El arte narrativo y la magia", Borges reclama la calidad de artificio para la literatura ahí donde los detalles narrativos que conforman una obra literaria tienen la facultad de suspender una duda permitiendo, de ese modo, la construcción de lo inverosímil y lo fantástico. Asimismo, Borges emplaza la propiedad maravillosa de la literatura ya que ésta conforma parte de la visión ontológica del mundo. Borges cree que hay dos tipos de logos estéticos; uno que se pone al servicio de la ciencia y que hace mimesis de la causalidad encontrada en el mundo así llamado "real"; y otro mundo, más vasto e indistinto, que se asemeja más a los artificios de la magia. En el citado ensayo sobre la magia, Borges manifiesta que:

\footnotetext{
La magia es la coronación o pesadilla de lo causal, no su contradicción. El milagro no es menos forastero en ese universo que en el de los astrónomos. Todas las leyes naturales lo rigen, y otras imaginarias. Para el supersticioso, hay una necesaria conexión no sólo entre un balazo y un muerto, sino entre un muerto y una maltratada efigie de cera o la rotura profética de un espejo o la sal que se vuelca o trece comensales terribles. (2005a: 243)
}

Para nuestro autor, la magia es entonces correlativa a todo aquello que rige "lo milagroso", en una palabra, lo fantástico. Es así como Borges, al descreer de la realidad como la concibe la ciencia, pone a la verdad como semblante de un mundo que jamás podría ser explicado por la lógica (aristotélica). Por ello, las ficciones que Borges ha escrito, pueden ser leídas como producto de cierta maravilla que deslumbra al intelecto, desbasando el concepto logocéntrico de la vida. La insistencia borgeana en la índole fantástica (mágica) de la realidad se debe, pues, a su creencia en el desorden nefasto del mundo, en el caos en que la humanidad entera habita, en suma, en la simulación remisa que ofrece la vida al querer ser albergada por los indefensos seres humanos que bregan incesantemente por encontrar el sentido último de su existencia.

Si ciertamente los estudios de Caillois y Todorov nos pueden proveer de elementos teóricos útiles para aproximarnos a la dinámica narratológica de los relatos fantásticos, nos atreveríamos a declarar que dentro de los mismos textos borgeanos se encuentra el germen técnico para vislumbrar su propia literatura. Es decir, una posible teoría de lo fantástico ya se encuentra fluyendo dentro de la literatura de Borges. Por lo tanto, nuestra labor será la de desentrañar sus raíces epistémicas y exponerlas tal cual, para darle sentido a la expresión fantástica-maravillosa de sus escritos. Para empezar, dos textos borgeanos nos permitirán dilucidar las bases fantásticas de su literatura. A partir de ellos podríamos analizar un vasto número de cuentos, bajo esa lentilla de lo fantástico y lo maravilloso. Ellos son "La flor de Coleridge" y "Magias parciales del Quijote", ambos recopilados en Otras inquisiciones.

Para Borges, la literatura fantástica adviene a partir de sus réditos. Estos podrían ser reductibles a cuatro, según la exposición que hace tanto en "La flor de Coleridge" como en "Magias parciales del Quijote": rimeramente, nuestro autor asume que la obra literaria nos puede conmover al nivel de lo fantástico porque se halla imbuida dentro de sí misma, es decir, 
acepta la contundencia del texto dentro del texto, el libro dentro del libro (metatextualidad); en segundo lugar, la realidad, según Borges, no es diáfana porque está constantemente emponzoñada por la ingerencia del sueño que, al final de cuentas, viene a ser lo mismo, vida y sueño son una misma cosa, productos hechos de una misma sustancia; tercero, el tiempo borgeano no es estático ni linear, es más, nosotros no vivimos en el tiempo, sino que él nos vive a nosotros, el sujeto es tal por cuanto se hace viajero en el tiempo; y finalmente, el tema del doble-especie de lo siniestro—se nos presenta constantemente afectando nuestra percepción de la realidad. Así, Borges propone estos cuatros postulados-el libro dentro del libro, el sueño, el viaje a través del tiempo y la cuestión del doble-para comprender el efecto fantástico de la escritura, y que los utiliza para componer su propia literatura.

El asunto de la metatextualidad es el primero de los elementos que Borges sugiere para crear cierta ilación fantástica literaria. El sustrato de este fenómeno lo postula magistralmente en "Magias parciales del 'Quijote". La "obra dentro de la obra" es una técnica que Borges considera elemental para instaurar el sentido ominoso de la realidad. El mejor ejemplo de esta especie es la historia de Don Quijote de la Mancha de Miguel de Cervantes y Saavedra. Como sabemos, los personajes del segundo libro del Quijote (1605) ya han leído la primera parte de sus aventuras (1615). Don Quijote y Sancho Panza saben que sus lances han sido leídos por otros individuos, y que sus andanzas ya son hartas conocidas por sus coterráneos. Para Borges, el exemplum quijotesco es el paradigma de la obra dentro de la obra ahí donde lo fantástico se manifiesta en el orden del desconcierto y el enajenamiento que produce en quien lo lee: "Ese juego de extrañas ambigüedades culmina en la segunda parte; los protagonistas han leído la primera, los protagonistas del Quijote son, así mismo, lectores del Quijote" (2005e: 49). A propósito, en "Borges: Una teoría de la literatura fantástica", Emir Rodríguez Monegal afirma que en la escritura de Borges "la misma obra literaria postula la realidad de su ficción al introducirse en el mundo que sus personajes habitan" (1977: 187). Con respecto a los personajes, Borges los lleva al extremo de la representabilidad implantando, de esa forma, el alcance fantástico de su literatura: los personajes (ficticios) son sus propios lectores.

Por ejemplo, personajes reales y actantes apócrifos se inmiscuyen en un mismo relato borgeano, proveyendo al lector de dudas posibles o certezas contradichas bajo la técnica mencionada de la metaficción-texto dentro del texto: Bioy Casares y Martínez Estrada toman parte en la narración de "Tlön, Uqbar, Orbis Tertius". Igualmente, Bernardo Haedo sobresale en "Funes, el memorioso". Patricio Gannon y Rodríguez Monegal hacen aparición de gala en "La otra muerte". Por otra parte, la ficción dentro de la ficción le permite a Borges trabajar con la relación, no sólo entre personajes, sino también con el recurso del narrador, o en su defecto, del autor. Al respecto, vuelve a mencionar Rodríguez Monegal en el citado artículo: "en todos los casos, un pedazo irrefutable de la realidad aparece injertado en la ficción; aparece lastrándola de la realidad" (1977: 187). Así lo podemos advertir en "El acercamiento a Almótasim” y "El examen de la obra de Herbert Quain", en donde los autores se relacionan, se (con)funden y se corresponden para crear el sentido siniestro del libro dentro del libro, más aún, del autor dentro del relato, del personaje siendo autor, del autor deviniendo en actante de la obra en cuestión. Esta técnica borgeana de la creación dentro de otra creación, o del autor siendo "escrito" por otro autor, le permite la posibilidad de erigir el sentido maravilloso dentro de su propia narración.

Otro ejemplo atinado sobre metaficción la encontramos también en Las mil y una noches, escrito al que Borges se refiere constantemente. Es una historia que se empotra dentro de otra, creando así una infinidad de relatos de la que depende la vida de quien la narra. Más 
adelante nos referiremos a la relación entre el elemento fantástico y el uso borgeano de las culturas ancestrales-la árabe en este caso-pero, por el momento, sólo nos cabe decir que Las mil y una noches, junto con Don Quijote, resulta en una especie de texto que sobrepasa las fronteras de la linealidad narrativa con el único fin de subvertir el orden cronológico y la lógica racional a la que estamos acostumbrados a barajar los lectores. La manera en que este texto está compuesto permite su aplicación fantástica dentro de una lectura no-convencional. En "Magias parciales del Quijote", nuestro autor acertadamente afirma, sobre Las mil y una noches, que este libro "maravilloso" trata de una "compilación de historias fantásticas (que) duplica y reduplica hasta el vértigo la ramificación de un cuento central en cuentos adventicios, pero no trata de graduar sus realidades, y el efecto, que debió ser profundo es superficial, como una alfombra persa" (2005a: 49). Así que no es fortuito que, el modelo de "la obra dentro de la obra" capaz de crear el extrañamiento como sentimiento siniestro de lo fantástico, se encuentre relacionado con las magias producidas por la lectura del Quijote, a través de un clásico de la literatura fantástica de la antigua Arabia, Las mil y una noches.

La táctica del sueño es la segunda técnica que utiliza Borges para crear el efecto fantástico dentro del relato. El propósito borgeano de enclavar el sueño en los eventos cotidianos es el de descomponer el concepto unívoco de la realidad. En "La flor de Coleridge", citando textualmente a Coleridge, Borges se (nos) pregunta; "Si un hombre atravesara el Paraíso en un sueño y le dieran una flor como prueba de que había estado ahí, y si al despertar encontrara esa flor en su mano... ¿ ¿entonces qué?" (2005a: 19). Esta descripción ominosa sobre el encuentro colindante entre sueño y vigilia nos revela el carácter siniestro de la vida ahí donde el sueño le confiere a ésta su calidad fantástica. Sin embargo, Borges va más allá de esa escritura sólo para advertirnos que, en la realidad de todos los días, sueño y vigilia son una misma cosa.

Talvez uno de los ejemplos narrativos borgeanos que mejor elucida este linde incierto entre realidad y sueño es el cuento "Las ruinas circulares", contenido en su libro Ficciones. En dicho texto, Borges explota el tema del sueño versus la realidad para crear el sentimiento fantástico dentro de su narrativa. En este cuento advertimos un asceta que decide soñar a un hombre, para una vez creado en sus más ignotos sueños, pueda éste, su hijo, (re)aparecer en la realidad, "El hijo que he engendrado me espera y no existirá si no voy" (2005c: 486). Su creación pasará de ser un sueño borroso a ser un hombre de carne y hueso cuyo único signo de irrealidad será su inmunización al fuego. El fuego revelará su condición irreal conjurando su estado de pura fantasía, es decir, su carácter de "soñado". El fuego jamás lo alcanzará. Sin embargo, hacia el final del relato, el asceta-padre de la criatura soñada-se encuentra en medio de un fuego devorador sabiendo que se acerca su final, pero llega a la realización de que él tampoco es consumido por las llamas: "con alivio, con humillación, con terror, comprendió que él también era una apariencia, que otro estaba soñándolo" (2005c: 487). Esta siniestra escena-cadena de alguien soñando a otro, cíclicamente, y así hasta el infinito, es uno de los recursos más efectivos que emplea Borges para producir en el lector el sentimiento fantásticomaravilloso de su escritura.

Junto al sueño y la metatextualidad a las que nos referimos en los párrafos anteriores, la cuestión del tiempo, o mejor dicho, el asunto del infinito, la eternidad y la circularidad temporal, es otro elemento que Borges utiliza para implantar el carácter fantástico dentro de su narrativa. Es un aspecto relevante al que nuestro autor igualmente se refiere en "La flor de Coleridge", sobre todo con relación al viaje a través del tiempo. Así, después de comunicar la interrogación de Coleridge sobre la aparición de la flor en el sueño para luego mostrarse en la 
realidad, Borges continúa preguntándose: "Más increíble que una flor celestial o que la flor de un sueño es la flor futura, la contradictoria flor cuyos átomos ahora ocupan otros lugares y no se combinaron aún" (2005c: 20). Esta flor sideral representa el viaje a través del tiempo, ése que debasa todo intento de sujetar la realidad en un momento fijo. La flor representa pues la infinitud, la expansión de la vida que bien puede ser vivida como un sueño, o en su defecto, el sueño que puede ser una parte significativa de la vida diurna y "real".

El viaje a través del tiempo, la creación de la inmortalidad o el acceso a la eternidad como duración sin límites son entonces frecuentes formas narrativas empleadas por Borges para crear ese talante fantástico de sus ficciones. Cuentos como "El inmortal", "La otra muerte", "El milagro secreto" o "Funes, el memorioso" son representaciones idóneas para ilustrar la cuestión del viaje en el tiempo. Recordemos que en "El milagro secreto" de Ficciones, el protagonista se encuentra suspendido en un tiempo desdoblado: un año que transcurre en un minuto (o un minuto que se desplaza a lo largo de un año). Hladík, el protagonista de este cuento, a través del narrador, se dice así mismo: "Pensó estoy en el infierno, estoy muerto. Pensó estoy loco. Pensó el tiempo se ha detenido. Luego reflexionó que en tal caso, también se hubiera detenido su pensamiento" (2005c: 549). El destino le ha concedido este don para que pueda ultimar su obra, hasta ahora inconclusa. Por su parte, en "El inmortal", ya desde su título, vemos esa insistencia en el tiempo interrumpido hasta el infinito. En este relato, el tiempo es desfasado, suspendido, derrotado. Dice Marco Flaminio Rufo, protagonista de la historia, "ser inmortal es baladí; menos el hombre, todas las criaturas lo son, pues ignoran la muerte; lo divino, lo terrible, lo incomprensible, es saberse inmortal" (2005d: 579). El tiempo, pues, no puede ser vivido en la linealidad de la lógica científica, sino que debe ser transmutado para que el sujeto pueda comprender, aunque sea a medias, la preñez de la vida.

Igualmente, en "Funes, el memorioso", el tiempo es el co-protagonista de la angustiante memoria de Funes: tiempo, memoria, recuerdo y olvido, se fusionan como un todo orgánico que lanza al individuo a la contemplación de un tiempo ilógico, circular, de pura ida y venida, de eterno retorno. En "Funes", la memoria milimétrica del protagonista reordena el tiempo haciendo que cada segundo vivido por él sea computarizado por sus interminables y memorables reminiscencias. El narrador y testigo del relato puntualiza aquí la vida atemporal y reminiscente del protagonista, Irineo: "Ahora su percepción y su memoria eran infalibles. Nosotros, de un vistazo, percibimos tres copas en una mesa; Funes, todos los vástagos y racimos y frutos que comprenden una parra" (2005c: 522). Curiosamente aquí no hay sueño, sólo vigilia, pero el elemento temporal ayuda, de igual medida, a construir la base maravillosa del relato: "Le era muy difícil dormir. Dormir es distraerse del mundo [...]" (2005c: 524). Finalmente, tenemos el cuento "La otra muerte", de su libro El Aleph, en el que magistralmente trabaja la cuestión del tiempo creando, de tal manera, cierta atmósfera de maravilla y estremecimiento en el lector. En este contexto, el tiempo convierte al texto en un relato fantástico ahí donde la temporalidad trasforma toda su "realidad". En este cuento, tenemos un sujeto que ejecuta un milagro "de vida y muerte" en donde el tiempo es su más probo aliado. Logradamente propone el narrador de este cuento que:

En la Suma Teológica se niega que Dios pueda hacer que lo pasado haya sido, pero nada se dice de la intrincada concatenación de causas y efectos, que es tan vasta y tan íntima que acaso no cabría anular un solo hecho remoto, por insignificante que fuera, sin invalidar el presente. Modificar el pasado no es modificar un solo hecho; es anular sus consecuencias, que tienden a ser infinitas. Dicho sea con otras palabras; es crear dos historias universales. (Borges 2005c: 615) 
La voluntad férrea de este hombre le permite recomponer el cauce del tiempo con respecto a una contingencia de su ser y su existencia. En este texto, el tiempo favorece al actante para que enmiende su entorno. El milagro consiste pues en usar las avenencias del tiempo en favor de la reconstrucción de toda una vida-ésa que incluye vida y muerte como un solo eslabón. Es por ello que Borges también recurre al uso del tiempo para erigir la ilusión fantástica de su literatura.

Finalmente, el tema del doble es la última de las técnicas borgeanas, esbozadas en este estudio, que introduciremos como elemento proclive a instaurar la sensación fantástica en aquél que se dispone a la lectura de sus relatos. El doble se puede interpretar a manera de un espejo que límpidamente reproduce una imagen-de sí mismo o del otro-suscitando algún tipo de extrañamiento en el lector. En "La flor de Coleridge", Borges vuelve a ofrecer varios ejemplos tomados de la literatura universal para proponer al "doble" como manifiesto de lo siniestro, eso que engendra la incursión de lo fantástico en la escritura. De la misma manera, el tema del doble está íntimamente relacionado con la cuestión del tiempo, sobre todo, el referente a los momentos posibles, a los instantes evanescentes o al tiempo inconcluso. Nuestro autor se solaza utilizando esta técnica, y muchos de sus cuentos están impregnados de este elemento del doble. Cuentos como "Tres versiones de Judas", "El tema del traidor y del héroe", "Los teólogos" y "Borges y yo" son algunos ejemplos narrativos que trabajan la cuestión del doble dentro del relato.

Por ejemplo, en "Tres versiones de Judas", de Ficciones, vemos a un doble fraccionado dentro de sus propios límites, causando en el lector ese estado de sobresalto y estremecimiento del que es capaz Borges por medio de su palabra. El elemento fantástico del doble se percibe cuando vemos que la Divinidad no se encarnó en Jesucristo sino en Judas, el traidor-momento de turbación. "Dios totalmente se hizo hombre pero hombre hasta la infamia, hombre hasta la reprobación y el abismo. Para salvarnos pudo elegir cualquiera de los destinos que traman la perpleja red de la historia; pudo ser Alejandro o Pitágoras o Rurik o Jesús; eligió un ínfimo destino: fue Judas" (2005c: 554). Este tipo de desdoblamiento (en el sentido del "doble" como producto) es el rédito al que recurre Borges para (re)presentar una "identificación" entre dos opuestos. Lo mismo ocurre en "Tema del traidor y del héroe" en donde el traidor deviene en el traicionado a partir de la intromisión de un doblaje actante que convierte la acción en puro semblante de la realidad: el héroe es víctima y la víctima es héroe. Por su parte, el relato de "Los teólogos" desabriga la cuestión del doble de manera harta siniestra, pues un hombre (un teólogo) incendia a su oponente con el fin de destruirlo y ganar para sí mismo la felicidad eterna, pero en el momento exacto de su muerte (he aquí la relación entre el doble y el tiempo como simultaneidad) se percata, por revelación divina, que él y su oponente son la misma persona. Para Dios los dos son un mismo organismo, ambos compuestos de una misma esencia: "Más correcto es decir que en el paraíso, Aureliano supo que para la insondable divinidad, él y Juan de Panonia (el ortodoxo y el hereje, el aborrecedor y el aborrecido, el acusador y la víctima) formaban una sola persona" (2005d: 595).

Finalmente, "Borges y yo" puede ser comprendido como un paradigma del sustrato más ominoso que representa el juego del doble. Este cuento, por medio del doblaje, se convierte en un relato fantástico porque, desde su comienzo hasta el final, el lector experimenta una molestia que se torna ora en duda ora en extrañamiento. Se nos revela en el cuento: "yo vivo, yo me dejo vivir, para que Borges pueda tramar su literatura y esa literatura me justifica [...]. Así mi vida es una fuga y todo lo pierdo y todo es del olvido, o del otro. No sé cuál de los 
dos escribe esta página" (2005f: 197). Podemos ver que dicho cuento tiene la capacidad estrepitosa de "importunar" a quien lee. Hacia el final del relato, el narrador, quien es a su vez autor y actante, acentúa dicha duda inicial al provocar la incertidumbre de quién de los dos (Borges o él mismo) escribió ese texto. Borges se ha dividido en dos personajes distintos quienes indudablemente comparten la esencia de una misma persona, al punto de no saber quién realmente escribió dicha página. Quizás el juego del doble sea el recurso borgeano más revelador en la trama considerada por él mismo como "fantástica". El doble le franquea al lector el carácter maravilloso y perturbador de la realidad presentada por la ficción, que en su defecto, para Borges, es "realidad pura". Como vimos, además del doble, la obra dentro de la obra, el trabajo onírico y el viaje en el tiempo son los arbitrios más frecuentes e importantes a los que recurre Borges para depositar cierto efecto fantástico en el ejercicio de su propia escritura, donde le permite al lector experimentar la conmoción que desencadena el lenguaje de lo maravilloso.

Por otra parte, el sentimiento fantástico encontrado en los textos borgeanos se debe, de igual manera, al uso frecuente y atinado, que hace nuestro autor, de los ambientes lejanos y de los parajes milenarios del Oriente. Borges se regocija en situar sus cuentos en el Cercano o el Lejano Oriente, en la India, en todas aquellas civilizaciones exóticas que mezclan la magia con la realidad, lo maravilloso con lo cotidiano, en una palabra, sociedades que construyeron su cultura con elementos fantásticos. Numerosas son sus referencias al Corán, Las mil y una noches, la Cábala y el Antiguo Testamento. En "Borges y las culturas orientales", Osvaldo Svanascini afirma que "en Kafka y sus precursores [Borges] cita a Han Yu, prosista del siglo IX, que extracta de la obra de Georges Margouliès. Traduce allí un fragmento de La captura del unicornio, del autor chino. De este singular escritor oriental cita de Margouliès otros temas como El dragón y la nube [...]" (1992: 347). En la misma línea advierte Pablo Tornielli: "Borges fue un devoto de la literatura, capaz de reverenciar un texto religioso por su carácter de clásico de la literatura (la Biblia y el Corán) o una doctrina filosófica por su valor literario (Schopenhauer, Berkeley, Swedenborg). Su devoción literaria fue más intensa que muchas devociones religiosas [...]" (2001: 5). Si continuamos con el ejercicio citatorio de Svanascini y Tornielli contaríamos con un sinnúmero de relatos borgeanos que indudablemente hacen referencia, tanto explícita como implícitamente, a temas relacionados con las culturas orientales, su filosofía y sus costumbres.

A este respecto, uno de esos textos borgeanos magistrales es "El jardín de los senderos que se bifurcan”, en donde cita a un tal Ts'ui Pen y su libro Hung Lu Meng. Esta referencia china le lleva a construir su teoría sobre el laberinto y sus correspondencias con el elemento fantástico de la realidad. Escribe Borges en este cuento: "Algo entiendo de laberintos: no en vano, soy bisnieto de aquel Ts'ui Pen, que fue gobernador de Yunnan y que renunció al poder temporal para escribir una novela que fuera todavía más populosa que el Hung Lu Meng y para edificar un laberinto en el que se perdieran todos los hombres" (2005c: 509). Así podemos conjeturar que los temas maravillosos empleados en muchos de sus relatos, así como aparecen en "El jardín de los senderos que se bifurcan", vienen dados por su génesis en la apreciación que hiciera Borges de las civilizaciones ancestrales del Oriente. Es más, sus tramas recurrentes sobre el sueño, el tiempo, el laberinto, el doble, los espejos y la muerte, por nombrar algunos de ellos, aparecen a partir de cierta conciencia sobre el influjo temático de estas culturas antiguas. 
Varios son los ensayos que Borges compuso para analizar la profundidad temática y filosófica de las culturas remotas, y de sus repercusiones en la vida denominada "real". "Una vindicación de la cábala", "El sueño de Coleridge", "La muralla y los libros", "Nathaniel Hawthorne", entre otros, son ejemplos prolijos de sus esfuerzos por examinar estos temas. Sin embargo, nuestro énfasis se posará en algunas de sus ficciones narrativas más representativas. Por ejemplo, en "La muerte y la brújula", Borges emplea elementos de la cábala para crear ese efecto agnóstico dentro del texto. Sobre este cuento atinadamente advierte Delfín Garasa que "la pista falsa es sugerida por una frase de la Kabbalah: La primera letra del nombre ha sido articulada [...] Borges admite que pueda confundírselo (a Dios) con la Muerte o la Nada. No olvidemos que en este cuento el detective y el asesino, la víctima y el victimario son una doble faz del mismo ser" (1988: 95). Borges, al introducir el símbolo de la cábala, le confiere al relato un tono filosófico (metafísico) para develar, de ese modo, la relación inherente entre verdad y apariencia: que es otra forma de engarzar el elemento fantástico en su literatura. Ya lo había dicho en el cuento "Tlön”: "La filosofía y la teología son, lo sospecho, dos especies de la literatura fantástica. Dos especies espléndidas" (2005c: 467). Por lo tanto, la utilización de símbolos orientales o mitos remotos le permite a nuestro autor añadir a su literatura cierto componente fantástico capaz de cuestionar al sujeto en el punto colindante entre su verdad y la ficción.

Otro de los cuentos que retoma el simbolismo del lejano Oriente es "El acercamiento a Almotásim", contenido en su libro Historia de la eternidad. El énfasis relacional del cuento se posa sobre el personaje que deviene enigmático, ajeno, incluso extraño, para aquéllos que se acercan a él. Su aspecto físico cambia constantemente produciendo una impresión ominosa en el lector. Este extrañamiento es posible por el carácter exótico, venido del Islam, elaborado a lo largo de todo el relato, y sobre todo, en la caracterización del nómada protagonista. La imagen islámica sirve aquí para investir al personaje principal con las propiedades de la divinidad-“emblema de Dios" o "ascenso místico". Hacia el final del cuento refiere el narrador: "Yo, con toda humildad, señalo un precursor lejano y posible: el cabalista de Jerusalén, Isaac Luria, que en el siglo XVI propaló que el alma de un antepasado o maestro puede entrar en el alma de un desdichado, para confortarlo o instruirlo. Ibbur se llama esta variedad de metempsicosis" (2005b: 447). Este cuento emplea de tal manera el escenario y la temática oriental ancestral para revelar el carácter ambiguo y metafísico de la narración (y del personaje) y, con ello, desencadenar en el lector la sensación fantástica deseada.

De igual manera, la temática islámica se deja ver en el relato "El Zahir". Este cuento nos recuerda que "[...] el Zahir es la sombra de la Rosa y la rasgadura del Velo [...]. Para perderse en Dios, los sufíes repiten su propio nombre o los noventa y nueve nombres divinos hasta que éstos ya nada quieren decir [...] quizá detrás de la montaña esté Dios" (2005d: 635). Uno de los temas principales de este relato es la cuestión del infinito y el enigma. Pare ello, Borges construye toda una red de motivos antiguos mahometanos con el fin de conducir al lector a la revelación del concepto del infinito que posee el carácter de ser imposible e indecible. Cita nombres antiguos y referencias islámicas con el fin de apoyar su tesis sobre el infinito: Rubaiyat, Umar ben Ibrahim al-Khayyami, Rumi, y el profeta Hákim, por nombrar algunos. De esta manera, el tema (el infinito) se mezcla con los motivos (islámicos) haciendo de esta obra un tratado metafísico-teológico de lo imperecedero, lo inmortal y lo absoluto.

Escenarios de la India y temática budista son también espacios empleados por Borges para recrear el efecto fantástico de sus relatos y, a la vez, construir un sistema epistemológico 
sobre el absurdo de la realidad y la teoría de lo maravilloso. Posiblemente "Las formas de una leyenda" es el texto que mejor ejemplifica esta relación entre budismo y lo absurdo. Osvaldo Svanascini declara al respecto que "tomando como fuentes el Buddahacarita, de Asvaghosha (Siglo I d. C.), el Lalitavistara y seguramente algunos Jakatas (vidas anteriores del Buda), condensa la vida del maestro indio, acotando o agregando interpretaciones del tema tan exhaustivamente tratado" (1992: 357). Como es habitual en la prosa borgeana, el autor indaga en la leyenda más allá del mito haciendo de su obra un tratado de historiografía y anécdota. Trabaja la fábula y ahonda en su rico simbolismo-budista en este caso-para proporcionar al lector con herramientas probas para comprender, o al menos vislumbrar, el lado paradójico e inadmisible de la así llamada realidad.

En definitiva, Borges ha construido su literatura-fantástica en sus fundamentosusando diferentes canales históricos, culturales, estéticos y filosóficos. Los ha empleado con sabiduría para desafiar al lector a divisar sus efectos, más allá de la bien conocida "realidad". Es más, en sus mismos relatos, y talvez sin advertirlo, construyó su propio tratado sobre literatura fantástica. En esta reflexión nos hemos abocado a reflexionar sobre cuatro instancias utilizadas por el mismo Borges con el fin de crear el efecto fantástico en sus cuentos. A esto hemos añadido el pertinente uso borgeano de la simbología de culturas antiguas del lejano Oriente. Posiblemente hayan más componentes de carácter fantástico-maravilloso en sus ficciones, pero estos cuatro-la metaficción, el sueño, el tiempo y el doble-serán suficientes para aprehender sus efectos narrativos y estéticos con el fin de advertir sus incidencias en la construcción de saber y verdad sobre qué es la vida y todo aquello relacionado con ella.

\section{Bibliografía}

Borges, Jorge Luis. 2005a. Discusión. Obras completas. Vol. I. Buenos Aires: Emecé.

2005b. Historia de la eternidad. Obras completas. Vol. I. Buenos Aires: Emecé.

2005c. Ficciones. Obras completas. Vol. I. Buenos Aires: Emecé.

2005d. El Aleph. Obras completas. Vol. I. Buenos Aires: Emecé.

2005e. Otras inquisiciones. Obras completas. Vol. II. Buenos Aires: Emecé.

2005f. El Hacedor. Obras completas. Vol. II. Buenos Aires: Emecé.

Caillois, Roger. 1970. Antología del cuento fantástico. Madrid: Pliegos.

Fernández Ferrer, Antonio. 1988. Borges A/Z. Madrid: Siruela.

Garasa, Delfín. 1988. “La Kabbalah y la muerte y la brújula”. Sefardica. 9 (1): 11-24.

Lord, Michel. 1998. "La organización sintagmática del relato fantástico". En: El relato fantástico. Antón Risco et al. (Eds.). Salamanca: Colegio de España. 11-41.

Páez Urdaneta, Rodrigo. 1988. “Prólogo”. Ficciones. Buenos Aires: Emecé.

Reisz de Rivarola, Susana. 1989. "Borges: Teoría y praxis de la ficción fantástica”. En: Teoría y análisis del texto literario. Buenos Aires: Hachette. 290-303.

Risco, Antón et al. (Eds.). 1998. El relato fantástico. Salamanca: Colegio de España.

Risco, Antón. 1998. "En las ruinas circulares (A propósito de un cuento de Borges)". En: El relato fantástico. Antón Risco et al. (Eds.). Salamanca: Colegio de España. 115-42. 
Rodríguez Fer, Claudio. 1998. "Borges: escepticismo y fantasía”. En: El relato fantástico. Antón Risco et al. (Eds.). Salamanca: Colegio de España. 143-68.

Rodríguez Monegal, Emir. 1977. "Borges: Una teoría de la literatura fantástica”. Revista Iberoamericana. 100-101: 177-89.

Svanascini, Osvaldo. 1992. "Borges y las culturas ancestrales". Cuadernos Hispanoamericanos. 505-507: 347-360.

Todorov, Tzvetan. 1981. Introducción a la literatura fantástica. México: Premia.

Tornielli, Pablo. 2001. “Algunos motivos árabes e islámicos en la obra de Borges”. Letras. 2 (1): $1-7$. 
